\title{
Integration of the e-Learning into the medical university curricula
}

\author{
Rusnakova $\mathrm{V}^{1}$, Bacharova $\mathrm{L}^{2}$, Simo $\mathrm{J}^{3}$, Krcmeryova $\mathrm{T}^{4}$, Finka $\mathrm{M}^{3}$, Kovac $\mathrm{R}^{5}$ \\ Slovak Medical University, Bratislava, Slovakia. viera.rusnakova@szu.sk
}

\begin{abstract}
Objectives: The aim of this contribution was to present the e-Learning introduction in the Slovak Medical University (SMU) with a focus on the implementation phase of the two blended courses - Healthcare Quality and Healthcare Professionals' Ethics.

Background: The introduction of the e-Learning was realized during the period 2008-2009 in the partnership of SMU and IBM Company, following strictly the project management approach.

Methods: The development of the e-module beta-versions was evaluated by the modules' authors using a structured interview. In a consequent pilot testing, the blended courses were evaluated by 23 students of the bachelor program in Rescue health care, and by 61 public health students at the master level program, respectively, using the standardized questionnaires.

Results: The tangible results included the documented SMU strategy for the e-Learning integration, six e-Learning modules and evaluation results. The authors' evaluation showed high scores for the experience in collaboration with IBM, as well as for the experience with the LMS environment. The students' evaluation showed a high acceptance of the e-Learning by both part-time and full-time students. The access to Internet was not recognized as a serious barrier.

Conclusion: The first experience with the integration of the e-Learning into the curricula of the Slovak Medical University showed the advantage of the systematic approach. The experience with developing the strategy in an interdisciplinary/ intercultural team, the knowledge about specific characteristics of distance learning by the involved SMU staff, and the know-how and skills represented the important benefits. It was demonstrated that the blended learning is recommended as optimal for the education in medical environment (Tab. 4, Fig. 1, Ref. 22). Full Text in PDF www.elis.sk.

Key words: e-Learning, university education, healthcare, quality management, professional ethics.
\end{abstract}

An extensive access to information and communication technologies (ICT) at universities, the continuous effort in quality improvement of the learning process as well as a high demand on the capacity of learning have resulted in an increased interest in innovation of the education and e-Learning. This trend is recognized also in Slovakia (Kukurova, 2006, Bachárová, 2009, Thurzo et al, 2010). However, the activities of universities in the developing and incorporation of e-Learning into curricula are still fragmented and anecdotal.

${ }^{1}$ Slovak Medical University, Bratislava, Slovakia, ${ }^{2}$ International Laser Center, Bratislava, Slovakia. ${ }^{3}$ IBM Slovakia, Bratislava, Slovakia, ${ }^{4}$ Faculty of Nursing and Health Professional Studies, Slovak Medical University, and ${ }^{5}$ Faculty of Public Health, Slovak Medical University, Bratislava, Slovakia

Address for correspondence: V. Rusnakova, MD, Slovak Medical University, Limbova 12, SK- 83303 Bratislava, Slovakia.

Phone: +421.2 .59370169$

Acknowledgement: We thank Ms. Milusa Baksova for her enthusiastic involvement in the preparation of the teaching materials, the questionnaires and the organization of pilot courses and their evaluation, as well as Ms. Katarina Ondruskova for her professional technical support during the modules development, providing numerous changes according to the authors' feedback. We also thank students for their participation at the pilot implementation of e-courses and their feedback.
The dominant style of education at the Slovak universities is still predominantly based on the classic face-to-face class lecturing. Following the current trends, the Slovak Medical University (SMU) decided to implement a systematic change and move from the traditional type of education to more interactive one, deriving benefit from the innovative technologies.

The Faculty of Public Health initiated a pilot e-Learning project, supported from the European Union - European Social Fund. The aim of this contribution was to present the design of the e-Learning modules on the healthcare quality and medical ethics that were included into this pilot project, with a special focus on the key features of the development and implementation phase of these blended courses.

\section{Material and methods}

The setting

The Slovak Medical University (SMU) with more then 50 year's history in the preparation of health care professionals operates as a state university. SMU is currently the regular part of higher education framework providing undergraduate, graduate, and postgraduate education in health care subjects and post-secondary specialization studies in medicine. The University is com- 


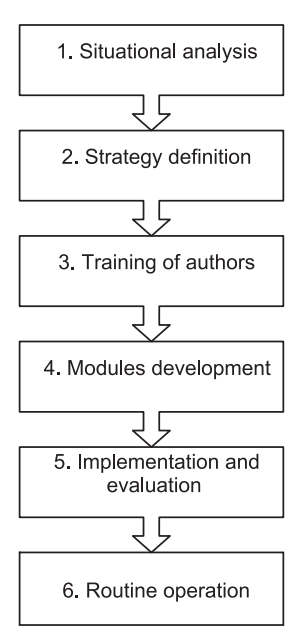

Fig. 1. The phases of the project.

posed of four faculties: Faculty of Medicine, Faculty of Nursing and Health Professional Studies, Faculty of Public Health, Faculty of Health in Banská Bystrica and a separate university research center. Although lecturers from three faculties were involved in the comprehensive e-Learning project, this study presents experience with the implementation of the e-Learning modules into public health and nursing programs.

\section{The Project}

The introduction of distance education and e-Learning was funded by the European Social Fund within the frame of the project "Distance learning support for students and staff SMU" (JPD NUTS II Bratislava DP 474/06-I/32-2.1) in the partnership of SMU and IBM company staff in the period 2008-2009. The key steps in the project development are described in the Figure 1.

The agreed project goals were to:

1) Develop strategy, methodology, and sequence of steps towards implementing the e-Learning;

2) Assure availability of resources necessary for starting the development of the e-Learning courses;

3) Verify the effectiveness of the implementation of the e-Learning modules into learning process in a pilot project; and

4) Evaluate the pilot experience and summarize recommendations for future action.

\section{Development of the e-Courses}

The software (SW) environment for the development of complete courses including testing was the authoring tool provided by $\operatorname{IBM}^{\circledR}(\mathrm{IBM}, 2006)$, and the development of the e-courses was supported by IBM consultants. A series of workshops was organized for authors/educators of the courses.

The first workshops were focused on the methodology of distance learning where the educational objectives were discussed in details with authors of the anticipated modules. The IBM 4 Tier Learning Model based on the revised Bloom Taxonomy of cognitive objectives for adult learning (Anderson, 2001) was rec- ommended to be applied in the development of the e-Learning modules, with the aim to move from the classical didactic way of teaching to more individualized and interactive one. Three distinctive levels were recognized in the formalization of the eLearning processes: 1) Learning from information (definitions, their applications, examples, glossary, access to web based resources, etc.), 2) Interactive learning (interactive exercises with a possibility to compare the students' results to the pre- prepared solutions), 3) Collaborative learning in interaction with a tutor (case studies, model situations, preparedness to change, and the feedback to small projects prepared in teams). The achievement of this level was restricted to the combination of the e-Learning and classroom-based teaching.

Then the necessary details of the proposed learning environment-IBM Workplace Collaborative Learning (WCL) technology (IBM Software, 2006) were explained to achieve the effective utilization of the system. The system allowed several interesting possibilities to follow the learning progress of students, such as the beginning and the end of the studying, the total study time spent, the number of attempts, the progress in the course and the tests results (final score). The system enabled also a direct e-mail contact between students and tutors that was essential for an effective governance and immediate reaction in the case of difficulties. Additional users' roles defined in the learning management system (LMS) such as administrator, manager, human resource manager, course manager that are available next to traditional student and tutor roles, were also presented.

\section{Evaluation}

Authors' evaluation

Five groups of authors evaluated the effectiveness of the training using a semi-quantitative interview after the development of the beta-version of modules. The following items were evaluated: effectiveness of training, project management support, use of WCL, planning and scheduling, utilization of e-Learning modalities, potential for increasing the number of students participating at courses, and satisfaction with the IMB consultancy.

\section{Students' evaluation:}

The e-Healthcare Quality course was implemented in the group of 61 Public Health students at the master level program (Mgr). Twenty seven full-time and thirty four part-time students were included in the pilot evaluation. The evaluation was performed using the two types of questionnaires. The first questionnaire was focused only on the evaluation of the e-Learning, and was distributed immediately after completing the e-Learning component. The questionnaire covered the following areas: content, form, understandability, scope of e-materials and effort needed for completing the module. The second questionnaire was distributed at the end of course after the exams. This questionnaire was based on the SMU regular evaluation form for education activities extended by the acceptance score for the e-course. The students' response rate was 23 of 27 and 32 of 34, respectively.

The e-Healthcare Professional Ethics course group consisted of 23 full time students of the bachelor degree program in Rescue 
Tab. 1. Defined knowledge and skills in quality assurance and improvement in health care achievable by students after completing the e-quality module.

\begin{tabular}{l|l}
\hline Generic competencies: & Organic competencies: \\
\hline - To understand basic concepts of \\
$\begin{array}{l}\text { quality management; } \\
\text { - To identify roles of stakeholders; } \\
\text { - To know roles and contribution of } \\
\text { leaders; }\end{array}$ & $\begin{array}{l}\text { improvement; } \\
\text { - To demonstrate skills in solution } \\
\text { of quality problems in the area of their } \\
\text { professional interest and influence; } \\
\text { - To identify the ways of quality } \\
\text { assessment in organization. }\end{array}$ \\
& $\begin{array}{l}\text { To analyze approaches to quality } \\
\text { assunce and improvement, } \\
\text { organizational and national levels; }\end{array}$ \\
& $\begin{array}{l}\text { To search for additional information } \\
\text { and to utilize up-to-date web based } \\
\text { and published sources. }\end{array}$ \\
\hline
\end{tabular}

health care. The questionnaire covered the similar areas as in the $\mathrm{HC}$ quality module. The students completed the questionnaires after the completion of the course. The response rate was 21 of 23 .

The quantitative data were analyzed using the exploratory analysis approach and nonparametric statistical methods (Kruskal-Walis test) using the XLSTAT statistical program.

\section{Results}

\section{Formulation of the SMU distance learning strategy}

The formulated strategic goals took into account the current structure of education at SMU as well as the principles of distance learning (SMU $2008 \mathrm{a}, \mathrm{b}$ ):

1) by the year 2011 the distance learning type of education is introduced at every Faculty of SMU and cover $20 \%$ of the undergraduate programs, $20 \%$ of the postgraduate specialization programs, $30 \%$ of the $\mathrm{PhD}$ program and $25 \%$ of the CME;

2 ) by the end of year 2010 the administration and organization of educational programs is completely supported by the learning management system.

The critical success factors were also formulated. The necessity to guarantee the identification of the faculty and top management of SMU with the new vision and strategy was stressed. The need for supportive environment with a strong personal involvement was emphasized. The sufficient financial support is required, including the multi-sources financing. And finally, the cross-sectional interdisciplinary teams have to be built systematically.

The general strategy comprised also the future steps after finishing the pilot project. It was recommended to: a) guarantee resources for the future deployment of the e-Learning as a relevant part of educational process; b) update existing study programs and analyze the needs for further development of the adequate e-Learning courses or programs in public; c) develop a plan for additional utilization of the technology used for the pilot project (Learning Management System - LMS), i.e. to use it as a tool for management and administration of learning programs, and not just for the individual courses delivery; (d) improve the communication within the institution and provide information for students and staff through enhanced, broadly utilized SMU Portal deploying LMS.

\section{Unified Design of the e-Courses}

A unified format for the e-courses was prepared by the designers and programmers from the project team, together with the authors of individual modules. A special attention was paid to the application of the user friendly GUI (graphical user interface) standards. The agreed design was used to indicate and emphasize the important points and aspects in the displayed text. The integral components of the course design were the course outlines in the form of the logical tree, the vocabulary, the interactive/ cross references, the self tests after each chapter, and the final test.

\section{Content of the e -HC Quality and e-HC Professional Ethic modules}

The e-Health Care Quality course was organized to allow its application in different types of educational programs. The equality course comprised the following basic chapters:

Introduction to Quality; Quality in Health Care; Leadership and Team Building; Quality Improvement Tools; Small Project Development Skills; External Quality Assessment. The learning objectives were aimed to achieve the adequate competencies in the health care quality management and are presented in the Table 1.

Healthcare Professional Ethics course has been prepared at the Faculty of Nursing and Health Professional Studies. The important parts of the professional ethics for health professionals were also prepared to a wider utilization in a variety of bachelor programs provided by the faculty. Three specific themes were prepared, which were related to the issues of the end of life, death and dying. The course consisted of the following chapters: Introduction to the Healthcare professional ethics, ethics of death and dying, euthanasia and ethics of organ transplantation. The learning objectives are presented in the Table 2 .

Tab. 2. Defined knowledge and skills achievable by students after completing the e-HC Professional Ethics module.

\begin{tabular}{|c|c|}
\hline Generic competencies: & Organic competencies: \\
\hline $\begin{array}{l}\text { - to obtain basic information about } \\
\text { the issues of dying and death } \\
\text { - to gain comprehensive information } \\
\text { about the terminal care of its } \\
\text { individual components, the types of } \\
\text { care for patients in the terminal stage } \\
\text { of disease } \\
\text { - to get basic information on the issue } \\
\text { of euthanasia and transplantation } \\
\text { - to develop sufficient basis for their } \\
\text { understanding and considering of } \\
\text { these topics }\end{array}$ & $\begin{array}{l}\text { - to define the basic concepts and } \\
\text { theoretical background associated with } \\
\text { dying and death, euthanasia and } \\
\text { transplantation } \\
\text { • to consider and analyze the various } \\
\text { arguments used in debates on this topics } \\
\text { • to focus on the issue of terminal care, } \\
\text { as they would in theory be prepared to } \\
\text { meet the dying man before entering } \\
\text { the clinical practice. } \\
\text { - to better understand the patient's } \\
\text { response, his relatives and other } \\
\text { stakeholders and find the optimal } \\
\text { solution of his difficulties in } \\
\text { connection with the options of care } \\
\text { for the terminally ill and dying } \\
\text { patients } \\
\text { - to provide professional care for the } \\
\text { patient in a spirit of respect for human } \\
\text { life until its end } \\
\text { - to respect the dignity of human beings } \\
\text { in accordance with the Health } \\
\text { Professional Code of Ethic }\end{array}$ \\
\hline
\end{tabular}


Tab. 3. Results for authors' feedback during the modules development.

\begin{tabular}{|c|c|c|c|c|c|c|c|}
\hline & Q1 & Q2 & Q3 & Q4 & Q5 & Q6 & Q7 \\
\hline & Training & Support & Use of WCL & Schedule/ plan & All modalities & $\begin{array}{c}\text { Teach more } \\
\text { students }\end{array}$ & $\begin{array}{c}\text { Future with } \\
\text { IBM }\end{array}$ \\
\hline Author 1 & 5 & 5 & 5 & 5 & 3 & 5 & 5 \\
\hline Author 2 & 4 & 5 & 5 & 3 & 5 & 5 & 5 \\
\hline Author 3 & 5 & 5 & 5 & 5 & 3 & 3 & 5 \\
\hline Author 4 & 5 & 5 & 5 & 5 & 3 & 5 & 5 \\
\hline Author 5 & 5 & 5 & 5 & 1 & 3 & 5 & 5 \\
\hline Total score & 24 & 25 & 25 & 19 & 17 & 23 & 25 \\
\hline Points on scale & 96 & 100 & 100 & 76 & 68 & 92 & 100 \\
\hline
\end{tabular}

Tab. 4. The students' feedback immediately after the e-Learning part of programs.

\begin{tabular}{|c|c|}
\hline Positive aspects: & Limitations: \\
\hline $\begin{array}{l}\text { - Possibility to study at home, in the own environment, anytime, any- } \\
\text { where, where is an access to Internet, } \\
\text { - e-Learning secures our time }\end{array}$ & $\begin{array}{l}\text { - Despite of saving time and comfortable regime of the study offered, it is } \\
\text { necessary to consider whether the introductory knowledge about particular } \\
\text { subject are available for students }\end{array}$ \\
\hline $\begin{array}{l}\text { - Possibility of self education with own pace of learning, accessible study } \\
\text { materials on one place presented in a systematic way, in good structured, } \\
\text { transparent and coherent form inclusive auto tests after each chapter and } \\
\text { final test at the end of module }\end{array}$ & $\begin{array}{l}\text { - Better to alternate e-Learning with face to face education, to guarantee the } \\
\text { space for the explanation and receiving immediate feedback from lecturer } \\
\text { to selected part of the chapter under the study }\end{array}$ \\
\hline $\begin{array}{l}\text { - Available model situations and examples of implementation of presented } \\
\text { subject and recommended tools; } \\
\text { - Direct access to additional information on Web; } \\
\text { - Immediate verification of the level of knowledge obtained in auto tests }\end{array}$ & $\begin{array}{l}\text { - to improve some technicalities of the e-Learning environment /system (final } \\
\text { test and, subchapters access) } \\
\text { - to explain installation specifics (Java) } \\
\text { - graphical design/environment - less load- burden on vision (colors, back- } \\
\text { ground, fonts used) }\end{array}$ \\
\hline $\begin{array}{l}\text { - Possibility to study subjects and themes of personal interest in deep, } \\
\text { available links to additional information, possibility to return to the topic }\end{array}$ & $\begin{array}{l}\text { - I don't like the dependence on the computer. If I would study only through } \\
\text { the internet I will have problem with using my time effectively since I have } \\
\text { not an access to internet continuously. Printed documents is possible to read } \\
\text { everywhere }\end{array}$ \\
\hline $\begin{array}{l}\text { - I would introduce /enlarge implementation of the e-Learning also to } \\
\text { other subjects and subsequent years (of the study) }\end{array}$ & $\begin{array}{l}\text { - e- mails from tutor to remind students progress in e-Learning were very } \\
\text { disturbing, more time on e-Learning and finishing e-Learning final test rec- } \\
\text { ommended by students (part time student comment) }\end{array}$ \\
\hline $\begin{array}{l}\text { - Possibility to match my learning to my activities, not activities to my } \\
\text { learning }\end{array}$ & - It will be better to devote more time for e-course \\
\hline - It is a new way of teaching, very interesting, enlightening and inspiring & - To extend the course content to other topics within the subject \\
\hline
\end{tabular}

\section{Evaluation of the pilot implementation}

\section{Authors'feedback during the modules development}

The results from a structured interview with authors are summarized in the Table 3. The highest average score is seen in the items Q2 "Support", Q3 "Use of WCL” and Q7 "Future partnership with IBM", where the evaluation was consistent in all authors, the lowest score in the item Q5 for utilization of all modalities of the e-course interactivity with students proposed within workshops for authors.

\section{The evaluation by students}

The results of the evaluation using the structured questionnaires showed a high acceptance of the e-Learning modules in both part-time students and full-time students. The difference between these two groups was not statistically significant.

The comments of students on the e-Learning positive aspects and limitations are summarized in Table 4.

\section{Discussion}

The main results of the pilot project could be divided to tan- gible and intangible. The tangible results included the clearly defined strategy in a written form, the six e-Learning modules and their implementation into the SMU curricula, and the results of evaluation. The experience with developing the strategy in an interdisciplinary/ intercultural team, the knowledge about specific characteristics of distance learning by both authors of the modules as well as the involved management representatives, and the know-how and skills represented the intangible results.

\section{Strategy development}

The creation of an adequate institutional strategy was a crucial step in the quality improvement. The bases for the discussion were the results of the preceding situational analysis that was performed in a close collaboration of the SMU management and IBM representatives, with the involvement of educators.

An important aspect of the strategy preparation was the building of the interdisciplinary team and the cultivation of the close collaboration within these teams. The interdisciplinary interaction had to harmonize the specifics of medical and non-medical healthcare professionals, as well as specifics of teachers/ tutors, 
managers and IT specialists. The effective interaction of all these professionals was then utilized not only in the management of the project, but also during the special training activities, and development and pilot implementation of e-courses.

A specific experience was the teambuilding considering two different organizational cultures: on the one hand the SMU represented a state healthcare educational organization, on the other hand the IBM, which represented a private for-profit ICT organization. The know-how and experience of both organizations resulted in a detailed plan, enabling an effective "managing of change" in terms of innovation model for service organization (Greenhalgh, 2004) during the project period. The tasks, responsibilities and timing were clearly defined, performed, checked and corrected, if necessary. The SMU provided discipline specific knowledge related to medicine and healthcare. The IBM managerial skills and previous experience in the field served as an exemplar both for the project management and for the learning and dissemination of these managerial skills within institution and contacted staff. The project management was consistent with the "make-it-happen" approach as opposed to the "let-it-happen" using the terminology of model mentioned above.

In some point, the openness of the communication across the firmly anchored organizational structure created a problem in achieving better end-results. The cross-sectional interdisciplinary team cultivation within SMU is therefore substantial for full sustainability of the project.

However, despite clearly defined strategic goals and intensive communication of critical success factors, there is a space for further optimization. Not all settled goals were fulfilled completely. The assurance of financial sustainability and the arrangement of expected multi-sources financing was not achieved during the pilot period.

Also, the LMS system was not introduced and maintained in a full extent; however the current level of technology enabled simple alternatives for continuing the started e-Learning process. The developed modules on $\mathrm{CD}$, together with distance learning experience earned by the staff, remained the integral part of the SMU educational activities.

\section{Modules development}

The e-Learning module unified design considered several aspects. The modules were design for several SMU programs: undergraduate, specialization studies and continuous medical education (CME). The identical graphical design enabling better orientation in all modules and highlighting important parts of the text was appreciated both by authors and students. The exposition to eLearning provided not only new professional competencies, but indirectly also improved computer literacy and foreign language skills of involved participants.

The presented e- Healthcare Quality and e-Healthcare Professional Ethics modules were designed and implemented for the undergraduate programs in public health and emergency care, however, modules are also applicable for other target groups, such as students of medicine, public health, nurses, as well as for other health care professionals. Its general content of the introductory e- parts and a great number of links to relevant Internet resources make it suitable for more universal utilization. In this way, the limited access to education materials in Slovak language is partly compensated.

The content of the e- Healthcare Quality course reflected the actual needs in healthcare management training in Slovakia (Kilíková and Jakušová, 2008, Bruchačova, 2001). The personal experience of authors in HC Quality and safety initiatives and management education were also considered (Parkes and Rusnáková, 2006, Rusnaková, 2006, Rusnaková, et al. 2004, Bachárová et al, 2000). The course was intended in an interactive mode also to reduce the gap between theoretical knowledge and practical designing, implementing and publishing quality improvement (QI) projects in participants' real health care settings. This gap has been repeatedly emphasized by international (Varkey, 2007, Davidoff, 2005, Henley, 2002, Harding, 2001) and Slovak professionals (Bacharova et al, 2000, Lenartova et al, 2007). So, a special attention was paid to the development of small quality improvement projects by students.

The similar approach was used in the development of the e-Healthcare Professional Ethics module. The content of the emodule was focused on death and dying. The education material was carefully selected and designed with respect to the high sensitivity of the topic and the specifics of the target group considering students' limited personal experience with death and dying. The application of e-Learning in this subject provided time necessary for the individual reflection of this difficult theme. Thus, the combination of the e-Learning and face-to-face teaching was applied.

As a result, both courses combine "classical" and e-Learning components, where e-Learning was used complementary to the class teaching. Students were gaining the sum of necessary knowledge during the e-Learning component. The required transformational leadership, critical appraisal abilities and team work skills were developed during the face-to-face classes organized mainly as a group work. This blended approach to e-Learning supported not only the cultivation of students' generic but also organic competencies (Raelin and Cooledge, 1995) in particular topics. The combination of e-Learning and classical components is recommended as a suitable application in e-Learning for $\mathrm{HC}$ environment (US Department of Education, 2009, Sisson et al, 2010). The students' acceptance of this blended learning was observed also in our study.

\section{The authors' feedback on modules development}

The process of modules development was managed by the IBM that has a long-lasting experience in preparation of e-Learning programs, as well as in their implementation in different educational settings, therefore the period of modules development was effective and motivating for authors. The modules development was a practical example of the PDCA cycle, with careful planning, defined action, regular checking of the progress and immediate corrections based on the feedback from authors and ICT specialists.

The comments from authors revealed that the participation in the project resulted also in re-thinking of education methodol- 
ogy and roles of educators, in fostering the interaction between lecturers, tutors and students, and in searching the optimum tools for students' active involvement and creative thinking support. The authors and tutor also stressed the usefulness of the reporting system offered by e-Learning platform that allowed to follow the students' progress in the learning process.

\section{Implementation and evaluation}

The quantitative evaluation of the pilot implementation of the both e-Healthcare Quality and e-Healthcare Professional Ethics modules by students consistently showed a high score. There were no statistically significant differences between the groups under the study (ethics versus quality, part time versus full time students).

In the qualitative evaluation, students stressed the main benefits of the e-Learning: the individual timing of study with the own time schedule of learning, the continuous access to the course information, a possibility to return to any course materials, and the opportunity of self testing. These reflections are in agreement with previously published experience with the e-Learning (U.S. Department of Education 2009, Sisson et al, 2010), as well as with expected benefits of our project.

The limitations mentioned by students were mostly related to ICT. The access to the Internet and compatibility between the individual users HW and SW possibilities and the LMS requirements created at the beginning some difficulties. However, the problem of compatibility was solved during the first period of the pilot implementation in majority of cases and did not interfere seriously with the progress in learning.

The students' high personal responsibility and self-motivation for learning is an important requirement for the successful e-Learning. This could be a limitation, especially in less mature and less motivated individuals. Moving from "teacher-driving learning" to "student-driving learning" was a substantial cultural change. The first experiences demonstrated that next to the e-Learning component it is still necessary to assure a direct interaction between students and tutors.

The results create a good platform for the continuation and spreading the e-Learning and distance learning at the Slovak Medical University. As was shown in this project, the adequate human, technological and financial resources are possibly mobilized and they were at disposal during the project period. For the sustainability and the future continuation of the general know how, human resources are already prepared and the technology is not more an issue. However, the innovation progress will constantly require the personal commitment of the management, authors and tutors time, its adequate planning and scheduling, and anchoring of the ad hoc created structures for the continuous support. The sufficient financial resources can be the critical factor anticipating multi-sources financing.

\section{Conclusion}

The first experience with the integration of the e-Learning into the curricula of the Slovak Medical University showed the advantage of the systematic approach. In general, the project can be considered as an example a good managerial practice covering necessary details in preparation and management of the education project.

The interdisciplinary collaboration between the e-Learning designers, consultants and faculty teams was a stimulating experience. The faculty benefited from the organized and team based approach to the e-Learning modules development and gained also a deeper understanding of distance learning methodology.

The pilot evaluation of the modules demonstrated that the blended learning is recommended as optimal for the education in medical environment as was similarly presented in other studies from medical environment.

It was also shown that the access to ICT and Internet was not recognized as a serious barrier for using the e-Learning by students.

The utilization of LMS in this project was focused mostly on the modules development and supervision of students. The LMS offers a space for broader utilization, and can be extended to the administration of all education activities. However, this step will require the necessary resources and a broader organizational change.

\section{References}

1. Anderson LW, Krathwohl DR, Airasian PW et al. A Taxonomy for Learning, Teaching, and Assessing - A Revision of Bloom's Taxonomy of Educational Objectives. Addison Wesley Longman, Inc. $2001 \mathrm{http} / /$ projects.coe.uga.edu/epltt/index.php?title=Bloom\%27s_Taxonomy

2. Bachárová L, Sedláková D, Kirchnerová J, Mladosievičová B. Research work and writing scientific papers as part of education at the Medical Faculty of Comenius University in Bratislava. Med Monitor 2008; 4 : $23-25$.

3. Brucháčová Z. Implementation guidelines for effective management of hospital accreditation. Bratisl Lek Listy 2001; 102 (3): 153-158

4. Bachárová L, Hlavačka $S$, Rusnáková V. Basic estimate of needs for training in evidence-based medicine in Slovakia. J Manag Med 2000; 14 (6): $362-382$.

5. Davidoff F, Batalden P. Toward stronger evidence on quality improvement. Draft publication guidelines: the beginning of a consensus project. Qual. Saf. Health Care 2005; 14 (5): 319-325.

6. Greenhalgh T, Robert G, Mac Farlane F, Bate P, Kyriakidou O. Diffusion of Innovations in Service Organizations: Systematic Review and Recommendation. Milbank Quarterly, 82 (4): 2004. http://www.milbank. org/quarterly/8204feat.html

7. Harding N, Ford J. Management and medicine: Marriage made in Heaven or time for a divorce? Bratisl Lek Listy 2001; 102 (1): 28-29.

8. Henley E. A quality improvement curriculum for medical students. Joint Com J Quality Improvement 2002; (28) 1: 42-48.

9. IBM Lotus Software ${ }^{\circledR}$ Workplace Collaborative Learning TM 2.6. http:// www-01.ibm.com/support/docview.wss?rs=0\&uid=swg21111893

10. IBM Workplace Collaborative Learning 2.6. ibm.com/redbook First Edition (July 2006). http://www.redbooks.ibm.com/redbooks.nsf/RedpieceAbstracts/sg247254.html?Open

11. Kilíková M, Jakušová V. Theory and practice of management in nursing. Martin: Osveta, 2008, 148 pp. 


\section{4-330}

12. Kukurová E, Králová E, Bergendi L', Marček T, Dzurenková D, Pekníková M, Traubner P. Universal algorithm managing the design of integrated teaching schemes. Bratislava: Asklepios, 2006, 60 pp.

13. Parkes A, Rusnáková V. HC Quality Assurance Plan Proposal. WB Slovakia/Health Sector Modernization Project - Component 2 - Quality of Care. Ministry of Health, SR, Bratislava 2006: 1-21.

14. Raelin JA, Cooledge AS. From generic to organic competencies. Human Resources Planning 1995; 18: 1-12.

15. Rusnáková V, Bachárová L, Boulton G, Hlavačka S, West Jr DJ. Assessment of management education and training for healthcare providers in the Slovak Republic. Hospital Topics 2004; 82 (3): 18-25.

16. Rusnáková V. Quality of Care Component. Final Report. WB Slovakia /Health Sector Modernization Project Component 2 - Quality of Care. Ministry of Health SR. Bratislava 2006; 1-16.

17. Sisson SD, Hill-Briggs F, Levine D. How to improve medical education website deisgn. BMC Medical Education 2010, 10:30. http://www. biomedcentral.com/1472-6920/10/30
18. Slovak Medical University. Situational analysis - Pilot project of distance learning. IBM/SZU, Bratislava 2008 a, 44 pp.

19. Slovak Medical University. Proposal of distance learning strategy and action plan. IBM/SZU, Bratislava 2008 b, 27 pp (in Slovak).

20. Thurzo A, Stanko P, Urbanova W, Lisý J, Suchancova B, Makovník M, Javorka V. The Web 2.0 induced paradigm in the e-Learning and the role of crowd sourcing in dental education. Bratisl. Lek Listy 2010; 111, $3,168-175$.

21. U.S. Department of Education, Office of Planning, Evaluation, and Policy Development. Evaluation of Evidence-Based Practices in Online Learning: A Meta-Analysis and Review of Online Learning Studies, Washington, D.C., 2009, 67 pp. http://www2.ed.gov/rschstat/eval/tech/evidencebased-practices/finalreport.pdf

22. Varkey P. Educating to improve patient care: Integrating quality improvement into a medical school curriculum. Amer J Med Quality 2007; 22 (2): 112-116. 